\title{
Intravenous salbutamol and aminophylline in asthma: a search for synergy
}

\author{
PDJ HANDSLIP, AM DART, BH DAVIES \\ From the Department of Respiratory Medicine and Asthma Research Unit, and the Department of \\ General Medicine, University Hospital of Wales, Cardiff
}

ABSTRACT The bronchodilation produced by increasing intravenous doses of aminophylline, salbutamol, and a combination of aminophylline and salbutamol given in random order was determined in 10 stable asthmatics on three consecutive days. On a fourth day, response to placebo injections was determined. Forced expiratory volume in one second $\left(\mathrm{FEV}_{1}\right)$ was measured at twominute intervals after each dose until $\mathrm{FEV}_{1}$ returned to a new baseline. At no dosage level was there synergy between the two agents in terms of either mean percentage increase in $\mathrm{FEV}_{1}$ or the integrated response. The failure to demonstrate synergy has implications both with respect to the clinical use and the underlying mechanism of action of these drugs.

$B_{2}$ adrenergic stimulants and methyl xanthine derivatives are commonly prescribed together in the management of asthma. $\mathbf{B}_{2}$ adrenergic stimulants increase production of cyclic $(3,5)$ adenosine monophosphate (cyclic AMP) from ATP by stimulation of adenyl cyclase. ${ }^{1}$ Methyl xanthine derivatives reduce the rate of degradation of cyclic AMP by inhibition of phosphodiesterase. ${ }^{2}$ Since $\mathbf{B}_{2}$ adrenergic stimulants and methyl xanthine derivatives produce increases in cyclic AMP concentration by different mechanisms, the question arises whether the interaction between these two classes of drug is synergistic ${ }^{3}$ - synergy being defined as an interaction between two agents when given in combination which produces a response greater than the sum of their individual responses.

Synergy has been demonstrated experimentally using guinea pig tracheal muscle, human leucocytes, and human lung fragments ${ }^{4-6}$ but has not been demonstrated conclusively in vivo. ${ }^{7-9}$ In an attempt to demonstrate synergy we have constructed doseresponse curves to intravenous salbutamol and aminophylline when given separately and in combination.

\section{Methods}

Ten well-controlled asthmatics requiring regular inhaled salbutamol and who showed greater than $15 \%$ improvement in forced expiratory volume $\left(\mathrm{FEV}_{1}\right)$

Address for reprint requests: Dr PDJ Handslip, Medical Unit, St Thomas' Hospital, London SE1 7EH. after inhalation of $200 \mu \mathrm{g}$ salbutamol gave informed consent. Subjects recorded peak expiratory flow rate (PEFR) and an asthma score for two weeks before investigation to establish stability. The subjects were fasting and had received no bronchodilator therapy for at least eight hours before study.

On three consecutive mornings an intravenous cannula was inserted and $\mathrm{FEV}_{1}$ values were recorded until consecutive values were identical. On three separate mornings salbutamol, aminophylline, or a combination of the two were given intravenously in random order, in increasing doses. The doses used were salbutamol $25,50,75,100,150,200 \mu \mathrm{g}$; aminophylline $25,50,75,100,150,200 \mathrm{mg}$; aminophylline + salbutamol $25,25: 50,50: 75,75: 100$, 100: $150,150: 200,200 \mathrm{mg} / \mu \mathrm{g}$.

After each bolus, FEV $_{1}$ values were recorded every two minutes taking the best of two values until $\mathrm{FEV}_{1}$ had returned to a stable baseline. The next bolus was then given. The maximum dose which could be given on any one day was determined by one of the following: the appearance of side-effects, the demonstration of no further increase in $\mathrm{FEV}_{1}$, or the limitation imposed by time taken at higher doses for the $\mathrm{FEV}_{1}$ to return to a new baseline. On the fourth morning the response to placebo injections was recorded.

\section{Results}

The mean pre-treatment values for $\mathrm{FEV}_{1}$ on the four study days show no statistically significant difference. 


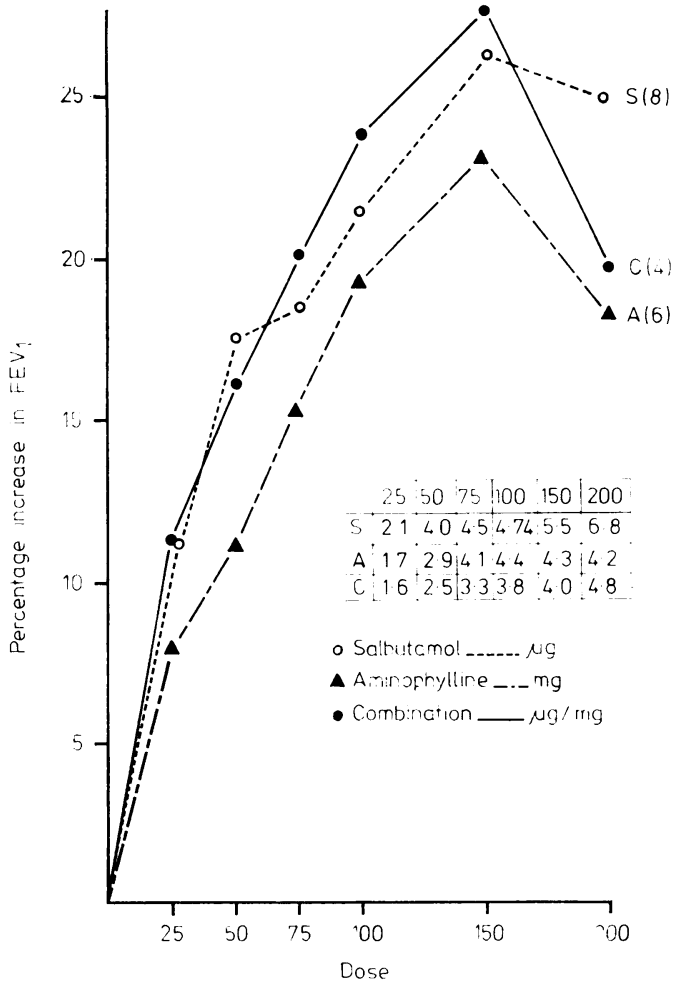

Fig 1 Mean percentage increase in FEV $V_{1}$ over daily baseline in 10 asthmatic patients (numbers in parentheses indicate number of patients who tolerated the $200 \mu \mathrm{g} / \mathrm{mg}$ dose). The table indicates the standard errors.

The $F E V_{1}$ responses produced by each injection were analysed in three different ways: increase in $\mathrm{FEV}_{1}$ from pre-treatment baseline to peak response was expressed as a percentage of the pre-treatment baseline-that is, percentage change in $\mathrm{FEV}_{1}$ over baseline. The mean values for percentage change in $\mathrm{FEV}_{1}$ are shown in fig 1 (the small table indicates the respective standard errors); no statistically significant response was seen to placebo injections. It can be seen that at 25 and $50 \mu \mathrm{g}$ doses of salbutamol the response is equivalent to salbutamol and aminophylline given in combination. However, at 75, 100, and $150 \mu \mathrm{g} / \mathrm{mg}$ the responses caused by the combination were greater. Statistical analysis of these results with paired $t$ testing and linear regression analysis showed a highly significant log dose response to all three drugs; however, the difference between salbutamol alone and the combination was not significantly different at these dosage levels.

Seven of the 10 patients showed a plateau in their dose-response curves at higher doses on all three treatment days, indicating that they were approaching their maximal response for that day. The im- provement in $\mathrm{FEV}_{1}$ values for these patients was expressed as a percentage of the maximum improvement in $F E V_{1}$ for that day. The mean responses are expressed in fig 2. Again, it can be seen that at 25 and $50 \mu \mathrm{g} / \mathrm{mg}$ the increases resulting from the combination are equivalent to salbutamol when given alone. However, at 75 and $100 \mu \mathrm{g} / \mathrm{mg}$ the responses resulting from the combination appear to be greater though the difference between the responses was not statistically significant.

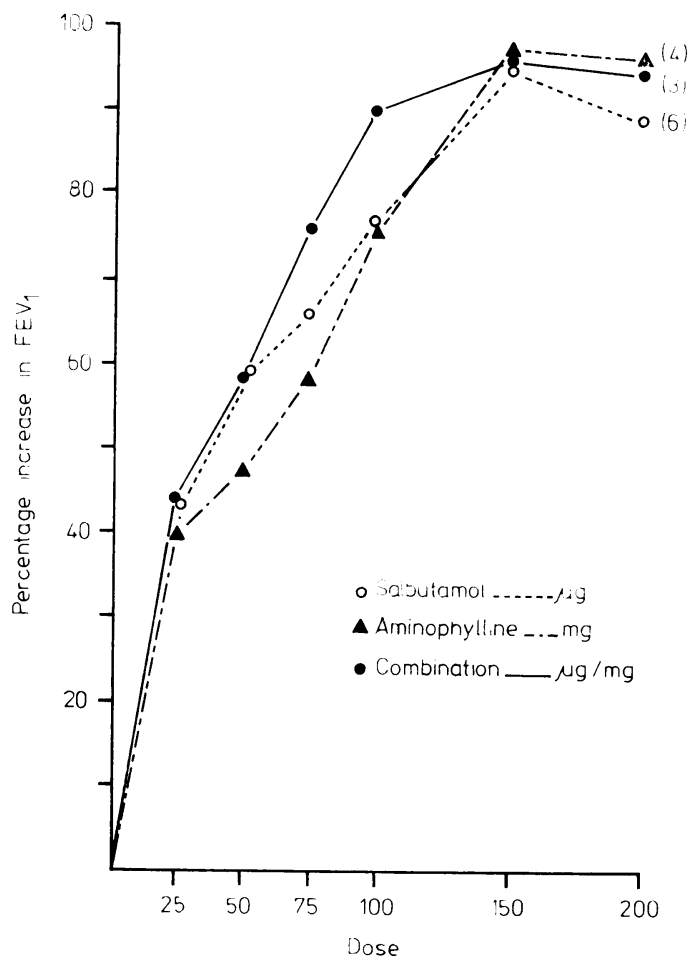

Fig 2 Mean percentage increase in FEV over maximum $\frac{7}{0}$ possible increase for seven patients who plateau between 100 and $200 \mu \mathrm{g} / \mathrm{mg}$ for all three drugs. (Number in parentheses indicate number of patients who tolerated the $200 \mu \mathrm{g} / \mathrm{mg}$ dose.)

Since the interaction between salbutamol and aminophylline may be related not to the peak response but to the area under the dose-response of curve, a computer analysis of the areas under the curve for each dose of each drug was performedintegrated response (see appendix). The results (fig 3 ) show that there was a highly significant dose response in each case $(p<0.01)$.

An individual comparison showed the combination to be significantly higher than aminophylline 


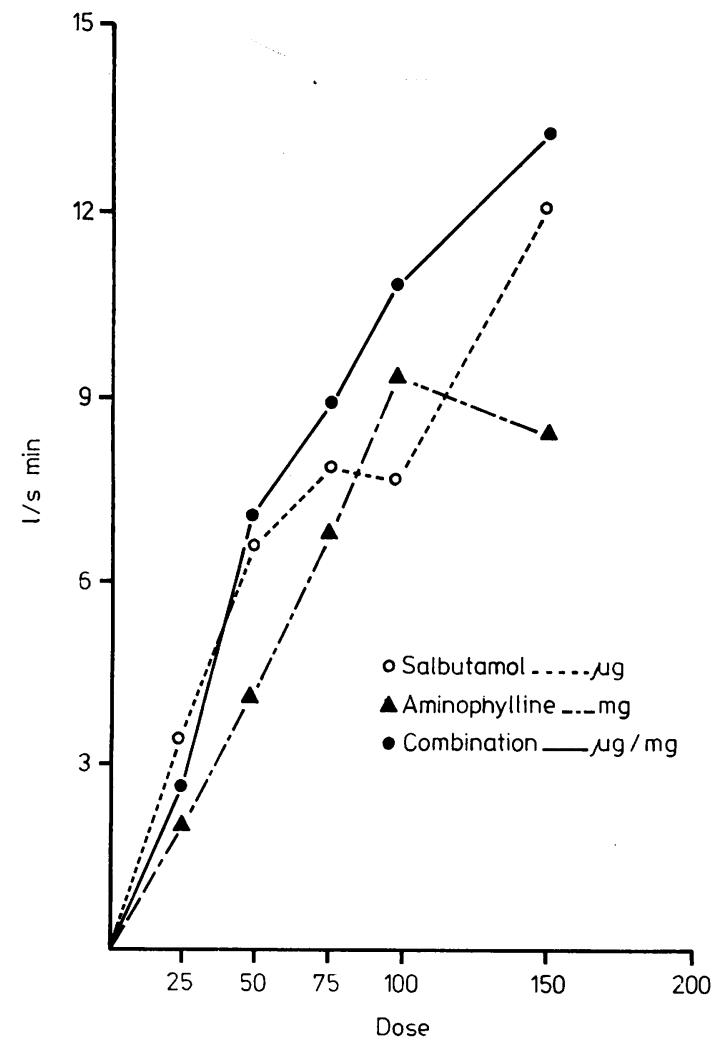

Fig 3 Mean integrated response for 10 asthmatic patients (see appendix).

alone $(\mathrm{p}<0.05)$. The linear regression lines for the three drugs were parallel and showed aminophylline to be lower than salbutamol, which was lower than the combination; however, the distance between the intercepts of the salbutamol and the combination dose-response regression lines was less than that between salbutamol and aminophylline, suggesting therefore that the response to aminophylline and salbutamol when given in combination is less than additive.

\section{Discussion}

We have demonstrated a dose-response relationship to small intravenous doses of salbutamol and aminophylline, which is statistically highly significant with respect to $\mathrm{FEV}_{1}$ response and "integrated response". If synergy between these drugs had occurred then one would have expected the dose response curve of salbutamol combined with aminophylline to be above and to the left of the salbutamo curve depicted (fig 1) -for example, if $75 \mathrm{mg}$ aminophylline produces a $15 \%$ improvement in $\mathrm{FEV}_{1}$ and $75 \mu \mathrm{g}$ salbutamol produces an $18 \%$ improvement in $\mathrm{FEV}_{1}$, then when the drugs are given in combination one would expect greater than $33 \%$ improvement in $F_{E V}$. The observed response was $20 \%$. Similarly, for all other doses used less than complete addition was seen when the drugs were given in combination.

The intravenous route was used in this study to avoid the variation in penetration associated with aerosol inhalation of bronchodilators. We have also avoided using different routes of administration since when an oral or intravenously administered drug produces a bronchodilator response, it will improve access of an inhaled drug so that any apparent interaction between the drugs may be caused partly by improved drug access rather than drug interaction. $F E V_{1}$ was used to detect changes in lung function because of its simplicity, reproducibility, and its demonstration of clinically significant changes in airway obstruction. Failure to demonstrate synergistic interaction between aminophylline and salbutamol in terms of reversal of airways obstruction may be caused by the lability of the airways in asthmatics though we were careful to select stable asthmatics.

Methyl xanthine derivatives and $B$ adrenergic stimulants have been shown to interact synergistically with respect to cyclic AMP levels in human lung fragments ${ }^{6}$; no such interaction has been shown in terms of improvement in FEV 1 . A factorially designed study has shown synergistic interaction with respect to $V \max 50$. This was statistically significant at 20 minutes only. In this study $250 \mathrm{mg}$ aminophylline was administered intravenously at the same time as an inhalation of $0 \cdot 16-0 \cdot 18 \mathrm{mg}$ of isoprenaline. ${ }^{7}$ The same author was unable to demonstrate synergy between oral choline theophyllinate and salmefamol with respect to PEFR.9 We have used standard dose-response curves to salbutamol, aminophylline, placebo, and salbutamol and aminophylline in combination and have shown highly significant increases in $\mathrm{FEV}_{1}$ and integrated response though we have been unable to show synergistic interaction. This calls into question the mechanism of action of $\mathbf{B}$ adrenergic stimulants and methyl xanthine derivatives.

It is proposed though not proven that $B$ adrenergic stimulants and methyl xanthine derivatives produce bronchodilation by increasing cyclic AMP levels in bronchial smooth muscle. Increased levels of intracellular cyclic AMP stimulate calcium binding to the cell membrane and the sarcoplasmic reticulum, calcium concentration in the myoplasm is thereby reduced and muscle relaxation occurs. ${ }^{10}$ It is suggested that the adrenaline-induced increase in calcium conductance in heart muscle results from an increase in the number of functional conductance channels. ${ }^{11}$ There is also evidence suggesting that low 
concentrations of $\mathbf{B}$ adrenergic agents may bypass adenyl cyclase and directly stimulate calcium conductance. ${ }^{12} \mathrm{~A}$ small pool of $\mathrm{B}$ receptors sufficient to initiate a maximal tissue response may not be coupled to adenyl cyclase or if coupled to adenyl cyclase the rise in cyclic AMP is too small to be measured. The remaining receptors or spare receptors may be responsible for most of the increase in cyclic AMP levels. ${ }^{13}$ B adrenergic stimulants and phosphodiesterase inhibitors used in combination may produce a 27-fold increase in "free" cyclic AMP while bound cyclic AMP increases three to four fold indicating that after the initial increase in cyclic AMP little additional binding of cyclic AMP to receptors would be expected to occur. ${ }^{14}$

In view of this information, although $B$ adrenergic stimulants and methyl xanthine derivatives might be expected to produce an additive or perhaps synergistic increase in cyclic AMP, we would not expect synergism with respect to bronchial smooth muscle relaxation. In this study the response to intravenous salbutamol and aminophylline when given in combination with respect to peak $F E V_{1}$ response and integrated response was less than would have been expected from the response when these drugs were given separately. Although we have demonstrated a small degree of addition, there was no evidence of synergy.

We are grateful to Dr MJ Campbell for his statistical help, to Professor GS Kilpatrick and Dr IA Campbell, and Miss Maureen McGurk.

\section{References}

${ }^{1}$ Robison GA, Butcher RW, Sutherland EW. Cyclic AMP. London and New York: Academic Press, 1971:146-231.

${ }^{2}$ Butcher RW, Sutherland EW. Adenosine 3',5'-phosphate in biological materials. Purification and properties of cyclic 3',5'-nucleotide phosphodiesterase and use of this enzyme to characterise adenosine $3^{\prime}, 5^{\prime}$-phosphate in human urine. J Biol Chem 1962;237:1244-50.

${ }^{3}$ Veldstra H. Synergism and potentiation. Pharmacol Rev $1956 ; 8: 339-87$.

4 Boksay I, Bollmann V. The effect of 3,7-dimethyl-1-(5oxo-hexyl) xanthine on the $\beta$-adrenergic receptors and on the activity of isoprenaline. Arch Int Pharmacodyn Ther $1971 ; 194: 174-80$.
${ }^{5}$ Lichtenstein LM, Margolis S. Histamine release in vitro: inhibition by catecholamines and methyl xanthines. Science 1968;161:902-3.

${ }^{6}$ Kaliner MA, Orange RP, Koopman WJ, Austen KF, Lavaia PJ. Cyclic adenosine $3^{\prime}, 5^{\prime}$-monophosphate in human lung. Biochem Biophys Acta 1971;252:160-4.

' Campbell IA, Middleton WG, McHardy GJ, Shotter MV, McKenzie R, Kay AB. Interaction between isoprenaline $\vec{\circ}$ and aminophylline in asthma. Thorax 1977;32:424-8.

${ }^{8}$ Leopold D, Handslip P. Additive interaction of amino- $\overrightarrow{\vec{\omega}}$ phylline and salbutamol in asthma: an in vivo study with

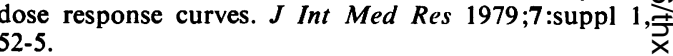
$52-5$

9 Dyson AJ, Campbell IA. Interaction between cholinew theophyllinate and Salmefamol in patients with re-. versible airways obstruction. Br J Clin Pharmacol 1977; $\vec{\circ}$ 4:677-82.

${ }^{10}$ Svedmyr N. Asthma treatment-pharmacological prin- $\rightarrow$ ciples and mechanism of drug action. Scand J Respir Diso 1977;101:13-24.

11 Reuter H, Scholz $H$. The regulation of the calcium con- ductance of cardiac muscle by adrenaline. $J$ Physio 1977;264:49-62.

12 Ingebretsen WR, Friedman WF, Mayer SE. Specificity of the action of isoproterenol on papillary muscle con- tractility. Fed Proc 1977;36:956.

${ }^{13}$ Kunos G. Adrenoceptors. Annu Rev Pharmacol Toxicol 1978;18:291-311.

14 Terasaki WL, Brooker G. Cardiac adenosine 3',5'-monophosphate. Free and bound forms in the isolated rat atrium. J Biol Chem 1977;252:1041-50.

Appendix

The areas were measured by a trapezoidal rule. Given that the $\mathrm{FEV}_{1}$ denoted by $\mathrm{x}_{1}, \mathrm{x}_{2} \ldots \mathrm{x}_{\mathrm{n}}$ are measured at $\mathrm{t}_{1}, \mathrm{t}_{2} \ldots \mathrm{t}_{\mathrm{n}}$ and the base line is $x_{b}$ the area is calculated by:

$$
\text { Area }=\frac{1}{2}_{1=2}^{n} \sum\left(\left(x_{1}-x_{b}\right)+\left(x_{1-1}-x_{b}\right)\right)\left(t_{1}-t_{1-1}\right) \text {. }
$$

$\mathrm{FEV}_{1}$ was measured in litres/s and time in minutes so that the area has units, (litres/s). minutes. The areas were calcu-. lated for each dose of each drug over 30 minutes. Resultsô extending beyond 30 minutes were ignored. If measurements were stopped before 30 minutes, $\mathrm{FEV}_{1}$ was assumed fixed from the last measurement to the end of the period and the area of this additional rectangle was recorded separately. The $D$ mean response and the variance of the response were plotted against dose. The variances increased roughly in proportion to the means. A linear regression analysis of $\log$ responseos against dose was conducted. The placebo dose and the $200^{\circ}$ $\mu \mathrm{g} / \mathrm{mg}$ dose were excluded. 